\title{
Vascular access conversion and patient outcome after hemodialysis initiation with a nonfunctional arteriovenous access: a prospective registry-based study
}

Natalia Alencar de Pinho ${ }^{1 *+}$ D , Raphael Coscas ${ }^{1,2+}$, Marie Metzger ${ }^{1}$, Michel Labeeuw ${ }^{3}$, Carole Ayav ${ }^{4,5}$, Christian Jacquelinet $^{6}$, Ziad A Massy ${ }^{1,7}$, Bénédicte Stengel ${ }^{1}$ and on behalf of the French REIN registry

\begin{abstract}
Background: Little is known about vascular access conversion and outcomes for patients starting hemodialysis with nonfunctional arteriovenous (AV) access. We assessed mortality risk associated with nonfunctional AV access at hemodialysis initiation, taking subsequent changes in vascular access into account.

Methods: We studied the 53,092 incident adult hemodialysis patients included in the French REIN registry from 2005 through 2012. AV access placed predialysis was considered nonfunctional when dialysis began with a central venous catheter. Information about vascular access changes was obtained from treatment modality updates.

Results: At hemodialysis initiation, AV access was functional for $47 \%$ of patients and nonfunctional for 9\%; $44 \%$ had a catheter alone. After a 3-year follow-up, 63\% of patients beginning hemodialysis with a nonfunctional AV access had changed to a functional one, $4 \%$ had had a transplant, 19\% had died before any vascular access change, and 13\% still used a catheter. Cox proportional hazard models with vascular access treated as a time-dependent variable showed an adjusted mortality hazard ratio (95\% confidence interval) for patients with nonfunctional AV access who subsequently converted to functional access of 0.95 (95\% Cl 0.89-1.03) compared with the reference group with functional AV access since first hemodialysis, versus $1.43(95 \% \mathrm{Cl} 1.31-1.55)$ for those who did not convert.

Conclusions: Among patients starting hemodialysis with a nonfunctional AV access, a substantial percentage may never experience successful vascular access conversion. Poor survival seems to be limited to these patients, while those who subsequently convert to functional $\mathrm{AV}$ access have similar mortality risk compared to patients with such access since hemodialysis initiation. Every effort should be made to obtain functional AV access in all suitable patients.
\end{abstract}

Keywords: Arteriovenous fistula, Catheter, Chronic hemodialysis, Epidemiology, Vascular access

\section{Background}

Survival of hemodialysis patients is strongly related to the type of vascular access. Numerous studies have shown that arteriovenous (AV) access (either fistulae or grafts) is associated with lower mortality [1-4] and fewer morbid events $[5,6]$ than central venous catheters.

\footnotetext{
* Correspondence: natalia.alencar-de-pinho@inserm.fr

${ }^{\dagger}$ Equal contributors

${ }^{1}$ Paris Saclay University, Paris-Sud Univ, UVSQ, CESP, INSERM, Renal and

Cardiovascular Epidemiology Team, Villejuif, France

Full list of author information is available at the end of the article
}

Guidelines for vascular access agree that AV access is the best option for hemodialysis patients, but there is no consensus about the optimal timing for creation, especially for AV fistulae [7-9]. Hence, AV access use at hemodialysis initiation does not come close to meeting current therapeutic goals [10]. Only $18 \%$ of US patients start hemodialysis with functional AV access, and this rate does not exceed 30 to $45 \%$ in Europe [2, 3, 11, 12].

The lack of functionality of a significant number of AV fistulae and grafts created before hemodialysis initiation results in initial catheter use. Nonfunctionality rates of about $18 \%$ are reported among the overall populations 
of incident hemodialysis patients in Canada and the US [2-4]. Rates as high as $45 \%$ have been observed in elderly patients with predialysis AV fistula creation [13]. Because of differences in patient selection and practices for AV access placement [14-16], nonfunctionality rates, their determinants, and outcomes may differ between Europe and North America. Only a few studies have investigated outcomes when AV access was nonfunctional at hemodialysis initiation, all of them in North America $[2,3,13]$. They report that survival is poorer with a nonfunctional than functional $\mathrm{AV}$ access and worst with catheters alone [2, 3]. High rates of vascular access conversion in patients starting dialysis with a nonfunctional AV access may explain their better outcome, as suggested by studies in patients who started with a catheter and subsequently converted to a functional AV access [17-19]. Nonetheless, considering outcomes specifically after hemodialysis initiation with nonfunctional AV access is important in the context of the current Fistula First Catheter Last initiative, which seeks to increase the use of AV fistulae in patients in whom they are deemed feasible [20]. We therefore used data from the French Renal Epidemiology and Information Network (REIN) registry to study changes of vascular access in patients starting hemodialysis with a nonfunctional AV access and the impact on outcome in a setting with relatively high AV access use.

\section{Methods}

\section{Population}

The French REIN registry includes all patients on renal replacement therapy (RRT) for end-stage renal disease (ESRD) - either dialysis or transplantation. It began in 2002 and progressively expanded to include the entire country in 2011. Details on methods and quality control of the REIN registry have been described elsewhere [21]. In this study, we considered the 55,847 patients who started hemodialysis from 2005 through 2012. After excluding minors $(n=370)$ and patients with missing vascular access data $(n=2385)$, we classified the remaining 53,092 patients according to their vascular access at hemodialysis initiation and by 2 data items (Fig. 1): 1/ "indicate if the vascular access at the first dialysis session was a catheter": "yes/no"; 2/"date of first AV access placement, even if it is not functional at dialysis initiation": "day/month/year". When the vascular access at the first hemodialysis session was not a catheter, patients were classified as having functional AV access, regardless of reported creation date $(n=25,153$, with missing dates for 3855). The remaining 27,939 patients who started hemodialysis with a catheter were divided into 2 groups according to the date of AV access creation: when the date preceded hemodialysis initiation, patients were considered to have nonfunctional AV access $(n=4705)$; if the date was after hemodialysis initiation (9030) or was

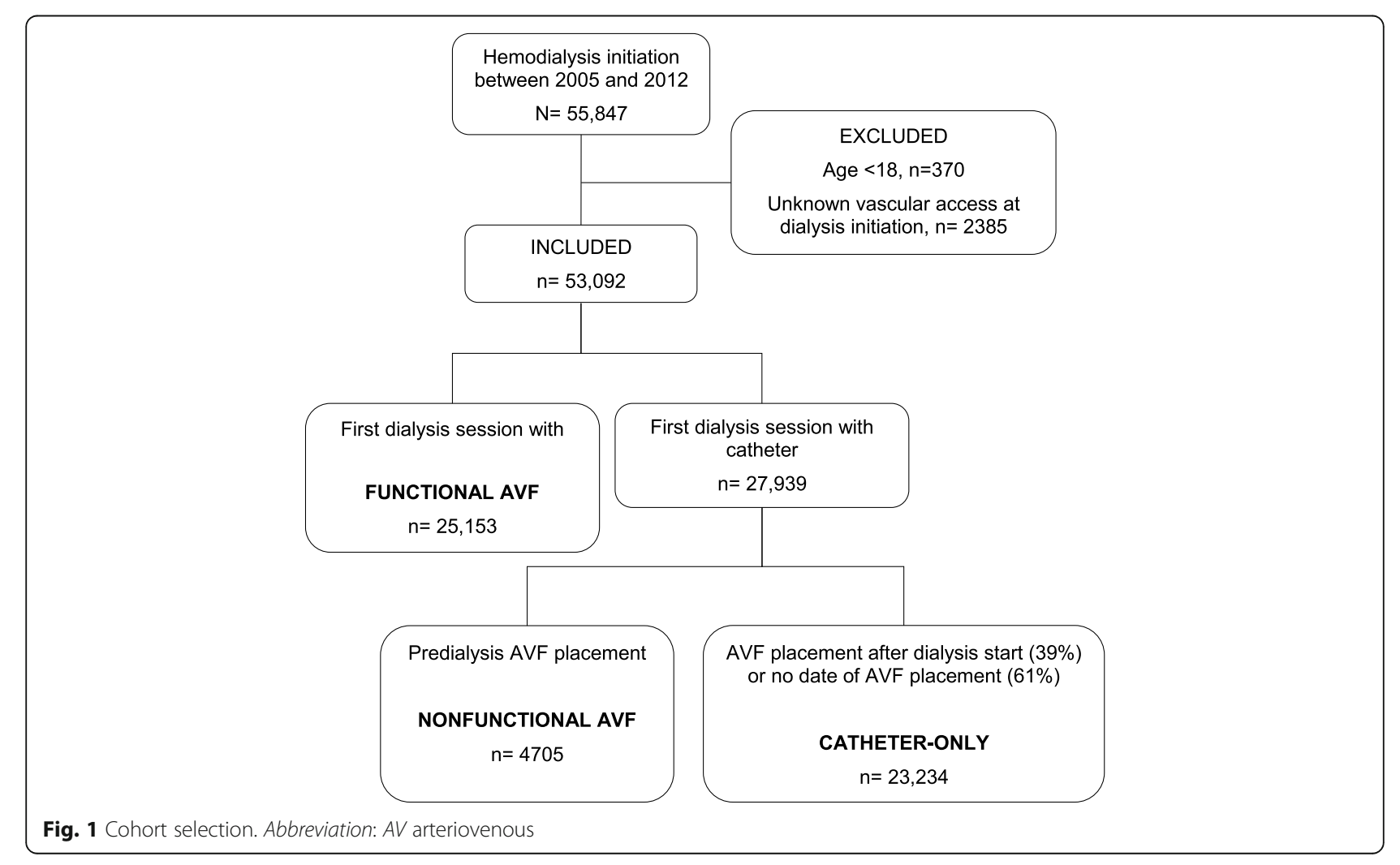


not reported $(14,204)$, patients were considered to have started hemodialysis with a catheter alone $(n=23,234)$. AV fistulae and AV grafts cannot be distinguished at hemodialysis initiation, but in 2013 only 3\% of prevalent patients in France had grafts [12].

\section{Outcomes}

Patients were followed up for mortality, kidney transplantation, peritoneal dialysis switch, and dialysis weaning until December 31, 2013. Information about vascular access changes was obtained from modality treatment updates or annual updates in the REIN registry, which report any permanent change (excluding one-off changes) and specify the type of AV access (fistulae or grafts).

\section{Statistical analyses}

Patient characteristics at baseline were described and compared between 3 groups defined by the type of vascular access at hemodialysis initiation, as described above: functional AV access, nonfunctional AV access, and catheter alone. Because of missing data for some variables (Table 1), we performed multiple imputation of 20 datasets with the fully conditional specification method [22, 23]. The imputation model included all variables in Table 1, as well as geographic region, year of first ESRD treatment, and vital status at the end of follow-up. Analyses through the 20 complete datasets were combined according to Rubin and Schencker's rules. We studied crude survival with the Kaplan-Meier method and compared the 3 vascular access groups by the log-rank test. We then used the cumulative incident function, with Gray's test, to estimate rates of conversion to functional AV access over 3 years, as well as those of renal transplantation, peritoneal dialysis switch, dialysis weaning, or death (whichever came first) as competing events, in patients who began hemodialysis with nonfunctional AV access or catheter alone [24]. We also estimated adjusted odds ratios for lack of vascular access conversion associated with patients' characteristics in these two subgroups. Finally, we used Cox proportional hazard models to estimate crude and sequentially adjusted cause-specific mortality hazard ratios (HRs) and $95 \%$ confidence intervals $(95 \% \mathrm{CI})$ associated with nonfunctional AV access (or catheter alone) at baseline, compared with functional AV access. HRs were first adjusted for demographic variables (age, gender, year of RRT initiation, and geographic region), then for clinical variables (comorbidities and laboratory values over the 1-month period before RRT), and finally for predialysis treatment with erythropoiesis-stimulating agents, dialysis start condition (planned or unplanned), and facility characteristics. A final model included vascular access as a time-dependent variable, which means that, for each death, the Cox model compared the current vascular access of patient(s) who died at time $t$ to that of all other patients who were at risk, i.e., alive on hemodialysis at that time [25].

Because changes in vascular access were not dated, but reported within update intervals, we hypothesized that they occurred at the midpoint of each update interval. We also restricted analysis to patients followed up at least 3 months because of the uncertainty about vascular access change reports in patients dying within the first 3 months of hemodialysis. Mortality rates per 1000 person-years were thus calculated considering the beginning of follow-up at 3 months. Conversions to functional AV access within the first 3 months were however taken into account for patients included in this analysis. We carried out 2 sensitivity analyses: one using the end instead of the midpoint of each update interval for vascular access, and other limiting the analysis to patients with at least one annual update (84\% of the study population). The proportional hazard assumption was assessed by plotting scaled Schoenfeld residuals versus rank time. Log-linearity was assessed for continuous variables. Two-sided significance tests were used and $P$-values $<0.05$ were considered significant. Robust variance estimates were used to account for facility clustering effects. All statistical analyses were performed with SAS 9.4 (SAS Institute Inc, Cary, NC).

\section{Results}

Patients' median age was 71 (IQR, 59-79) years, 63\% were men, $40 \%$ had diabetes and $30 \%$ at least 2 cardiovascular comorbidities. Dialysis start was unplanned for $33 \%$. Overall, $44 \%$ started dialysis with a catheter alone, and $56 \%$ after predialysis AV access placement: $47 \%$ were functional and $9 \%$ nonfunctional. The percentage of patients with predialysis $\mathrm{AV}$ access placement decreased significantly from $60 \%$ in 2005 to $54 \%$ in 2012 ( $P$-value for trend $<0.001)$ while that of nonfunctional AV access remained stable. Table 1 summarizes patient characteristics according to vascular access type at the start of hemodialysis.

\section{Changes in vascular access}

The median follow-up was 3 years (range 1-9 years). Most patients (96\%) had updated vascular access information in the first 3 months of hemodialysis; 91, 88, and $84 \%$ had updated information in the first, second, and third year of follow-up, respectively. Overall, $75 \%$ of patients alive on hemodialysis at 12 months had functional AV access, $81 \%$ at 24 months, and $84 \%$ at 36 months. These percentages were lower for patients with nonfunctional AV access at baseline than for those with functional AV access, but higher than for patients with catheter alone (Additional file 1). Of note, between 
Table 1 Patient characteristics according to vascular access at hemodialysis initiation

\begin{tabular}{|c|c|c|c|c|}
\hline Characteristics & $\begin{array}{l}\text { Functional AV access } \\
n=25,153\end{array}$ & $\begin{array}{l}\text { Nonfunctional AV access } \\
n=4705\end{array}$ & $\begin{array}{l}\text { Catheter only } \\
n=23,234\end{array}$ & $\begin{array}{l}\text { Imputed missing } \\
\text { data (\%) }\end{array}$ \\
\hline Men & 65.0 & 58.2 & 62.0 & 0 \\
\hline Age (years, median (IQR)) & $70.4(58.2-78.6)$ & $70.6(59.6-78.9)$ & $72.0(59.6-80.3)$ & 0 \\
\hline \multicolumn{5}{|l|}{ Primary renal disease } \\
\hline Hypertensive/Vascular & 27.3 & 26.5 & 25.4 & \\
\hline Diabetic nephropathy & 23.1 & 30.9 & 21.4 & \\
\hline Glomerulonephritis & 12.0 & 9.1 & 9.6 & 0 \\
\hline Polycystic kidney disease & 9.7 & 4.5 & 2.3 & \\
\hline Other & 16.6 & 17.9 & 26.2 & \\
\hline Unknown & 11.2 & 11.1 & 15.3 & \\
\hline Diabetes & 38.5 & 49.0 & 39.8 & 1.5 \\
\hline \multicolumn{5}{|c|}{ Number of cardiovascular comorbidities } \\
\hline 0 & 48.8 & 40.1 & 40.9 & \\
\hline 1 & 25.5 & 26.3 & 24.6 & \\
\hline 2 & 15.1 & 17.5 & 18.4 & 5.8 \\
\hline 3 & 7.5 & 10.9 & 11.0 & \\
\hline 4 or 5 & 3.1 & 5.2 & 5.2 & \\
\hline Lower limb amputation & 2.3 & 4.3 & 4.3 & 5.6 \\
\hline Malignancy & 8.2 & 9.5 & 15.1 & 3.1 \\
\hline \multicolumn{5}{|l|}{ Mobility status } \\
\hline Autonomous & 87.1 & 79.5 & 72.2 & \\
\hline Needs assistance & 9.9 & 14.9 & 18.8 & 13.6 \\
\hline Totally dependent & 3.0 & 5.7 & 9.1 & \\
\hline \multicolumn{5}{|l|}{ Body mass index $\left(\mathrm{kg} / \mathrm{m}^{2}\right)$} \\
\hline$<18.5$ & 4.7 & 5.5 & 8.0 & \\
\hline$[18.5-25.0]$ & 40.9 & 38.4 & 44.6 & 26.4 \\
\hline$[25.0-30.0]$ & 32.5 & 30.6 & 28.9 & \\
\hline$\geq 30.0$ & 21.9 & 25.5 & 18.4 & \\
\hline Serum albumin $(g / l$, mean $\pm S D)$ & $35.0 \pm 5.9$ & $32.5 \pm 6.2$ & $30.9 \pm 6.4$ & 43.9 \\
\hline Hemoglobin $(\mathrm{g} / \mathrm{dl}$, mean $\pm \mathrm{SD})$ & $10.6 \pm 1.6$ & $10.1 \pm 1.7$ & $9.7 \pm 1.8$ & 21.0 \\
\hline Predialysis ESA treatment & 59.2 & 55.0 & 31.1 & 9.7 \\
\hline \multicolumn{5}{|c|}{ Estimated glomerular filtration rate (MDRD $\mathrm{ml} / \mathrm{min} / 1.73 \mathrm{~m}^{2}$ ) } \\
\hline $\mathrm{eGFR} \leq 5$ & 8.7 & 13.2 & 17.7 & \\
\hline $5<\mathrm{eGFR} \leq 10$ & 53.9 & 52.8 & 47.4 & \\
\hline $10<\mathrm{eGFR} \leq 15$ & 28.9 & 25.3 & 23.9 & 17.4 \\
\hline $15<\mathrm{eGFR} \leq 20$ & 6.7 & 6.4 & 7.3 & \\
\hline eGFR $>20$ & 1.8 & 2.3 & 3.6 & \\
\hline Unplanned dialysis start & 9.5 & 37.7 & 56.9 & 2.8 \\
\hline \multicolumn{5}{|l|}{ Facility type } \\
\hline In center & 92.0 & 96.9 & 98.3 & \\
\hline Satellite unit & 4.0 & 1.5 & 1.0 & 0 \\
\hline Self-dialysis & 4.0 & 1.6 & 0.7 & \\
\hline
\end{tabular}


Table 1 Patient characteristics according to vascular access at hemodialysis initiation (Continued)

\begin{tabular}{lccc}
\hline Facility ownership & & 27.3 & 30.9 \\
Public university & 17.9 & 31.7 & 31.6 \\
Public non-university & 29.8 & 30.3 & 28.8 \\
Private for-profit & 34.0 & 10.7 & 8.8 \\
Private not-for-profit & 18.4 & & 0 \\
\hline Abbreviations: $A V$ arteriovenous, $C$ confidence interval, IQR interquartile range, SD standard deviation, ESA erythropoiesis-stimulating agents, MDRD Modification of \\
Diet in Renal Disease. $P$ values of the comparisons between the 3 groups were statistically significant at $<0.0001$ for every characteristic in Table 1
\end{tabular}

2 and $3 \%$ of patients classified with functional AVF actually had a functional AV graft at these time points, with no significant difference among groups. At the end of follow-up, 3075 (65.4\%) and 10,156 (43.7\%) patients in the nonfunctional AV access group and catheter-only group, respectively, have had at least one conversion to functional AV access. The cumulative incidence of vascular access conversion, with death and renal transplantation treated as competing events, was higher in patients with nonfunctional AV access at hemodialysis initiation than in those with catheters alone. Patients with catheter alone at dialysis initiation were nearly twice as likely to die before any reported conversion to functional AV access as those starting dialysis with nonfunctional AV access (Fig. 2a and b). Factors associated with lack of conversion to functional AV access in patients with either nonfunctional AV access or catheter only at baseline are shown in Table 2. Overall, patients who did not convert to a functional AV access were older, most often women, and had poorer health condition. However, the effect of age, malignancy, and poor mobility status on the lack of access conversion appeared to be stronger in patients with catheter only as compared to those with nonfunctional AV access at baseline.

\section{Mortality associated with nonfunctional AV access}

During the study period, 22,635 (43\%) patients died (of whom 3419 within the first three months of dialysis), 7935 (15\%) had kidney transplantation, and 19,100 (36\%) remained on hemodialysis. Other outcomes included switch to peritoneal dialysis (3\%), dialysis weaning (3\%), and loss to follow-up (1\%). Kaplan-Meier curves comparing the three vascular access groups at hemodialysis initiation showed survival was best in the functional AV access group, intermediate in the nonfunctional AV access group, and poorest in the catheter alone group (log-rank $P$-value $<0.0001$; Additional file 2 ). Cox proportional hazard models showed that the excess risk associated with nonfunctional AV access at hemodialysis initiation was strongly attenuated after adjustment for clinical factors, but remained a significant 10\% higher after full adjustment (Additional file 3). The risk of death was lower for patients with nonfunctional AV access than for the catheter alone group. After changes in vascular access were considered, the mortality risk of patients with nonfunctional AV access who subsequently acquired functional access was similar to that of patients whose AV access was functional from the start (Fig. 3). Patients starting dialysis with a catheter alone had the highest risk of death when they continued with a catheter, and the lowest risk if they subsequently acquired a functional AV access. Hazard ratios were stable over time as indicated by the Schoenfeld residual plot (data not shown) Sensitivity analyses using the end instead of the midpoint of each update interval for vascular access or limiting the analysis to patients with at least one annual update did not materially alter these findings (Table 3).

\section{Discussion}

This study shows that in France, where the rate of predialysis AV access placement is relatively high, nonfunctional AV access at hemodialysis initiation is common and does not appear to have decreased over time. A substantial percentage of patients with nonfunctional AV access at first hemodialysis may never acquire a functional AV access which is associated with increased mortality risk. In contrast, the outcome of patients with a nonfunctional AV access converting to a functional one appears similar to that of those starting with a functional AV access. These findings have important implications for clinical practice and public health policies.

The $9 \%$ frequency of nonfunctional AV access at hemodialysis initiation in our study is of the same order of magnitude as that reported in Canada (9\%) [4], but lower than in the US $(18 \%)[2,3]$. Nevertheless, the relative weight of nonfunctional AV accesses among all those created predialysis was much lower in France than in North America. About $16 \%$ of patients with predialysis AV access started hemodialysis with a catheter in France, while this percentage was 33\% in Canada and about $50 \%$ in the US. The Dialysis Outcomes and Practice Patterns Study (DOPPS) has pointed out several differences in both patient characteristics and clinical practices between Europe and North America that may explain this discrepancy. For instance, hemodialysis patients in North America have more comorbidities than 


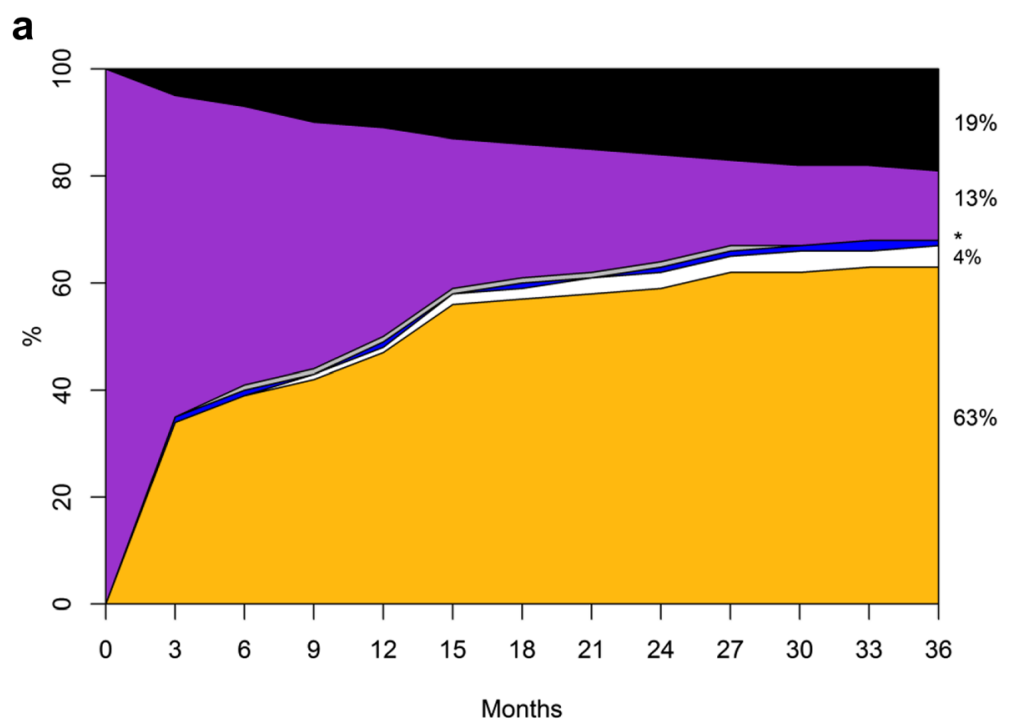

b

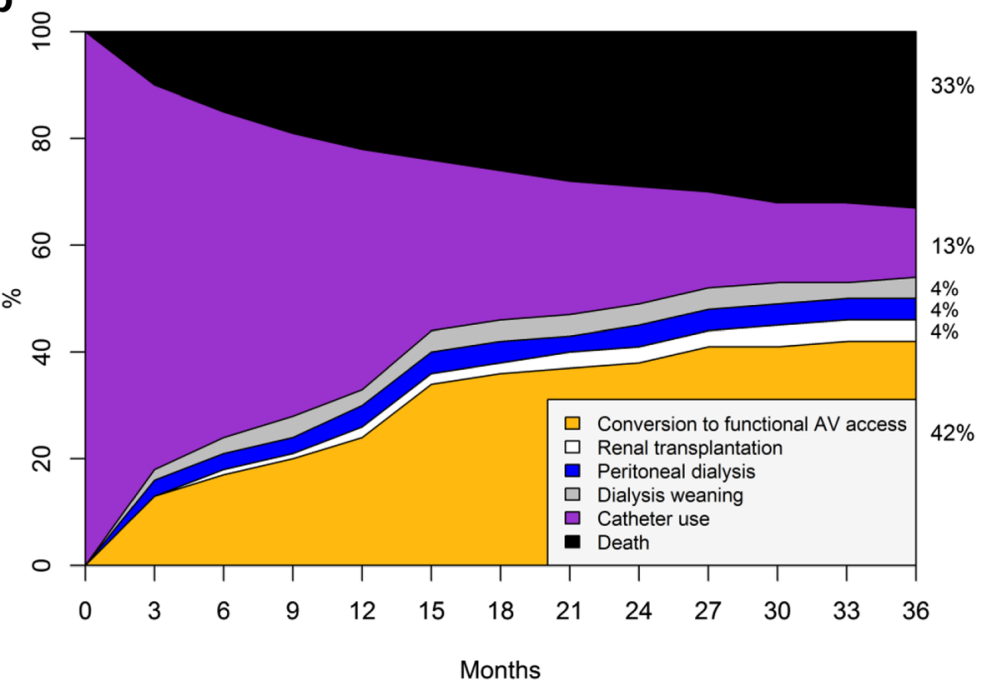

Fig. 2 Cumulative incidence ${ }^{\#}$ of vascular access conversion to functional AV access. (a) Nonfunctional AV access group and (b) Catheter only group at hemodialysis initiation. ${ }^{\#}$ Competing risks considered were renal transplantation, peritoneal dialysis switch, dialysis weaning, and death, whichever came first. Gray's test $P$-value (nonfunctional AV access versus catheter only): conversion to functional AV access, peritoneal dialysis switch, dialysis weaning, and death, $<0.0001$; renal transplantation, 0.04. Abbreviation: AV arteriovenous. *Cumulative incidence of peritoneal dialysis and dialysis weaning in the nonfunctional AV access group: 0.8 and $0.7 \%$, respectively

those in Europe [26], and these are well established determinants of poor AV access use and patency [27, 28]. Most striking, however, are the differences in practices. Not only are rates of AV access at hemodialysis initiation in Europe substantially higher than in North America [14, 29], but surgical training has been shown to differ between these 2 regions, and more training with $\mathrm{AV}$ access, as found in Europe, is associated with both AV access creation and patency [30]. Once an AV access is placed, the involvement of the access surgeon in monitoring it for maturation and functional use or in planning for another access in case of failure may impact functionality rates. Nevertheless, information is lacking about the relationship of the access surgeon to the dialysis patient after AV access is placed. Earlier AV fistula cannulation in European countries [14] may also partly explain the lower prevalence of nonfunctional AV access in our study.

As expected, nonfunctional AV access at hemodialysis initiation was associated with an increase of $10 \%$ in overall mortality risk, compared with functional AV access. Since AV fistulae account for $97 \%$ of the AV access in France, this increased risk is lower than the 30\% excess mortality associated with maturing compared with mature AV fistulae observed in all US adult patients who started dialysis between 2006 and 2010 [3]. This excess mortality risk was even higher in elderly patients in the 
Table 2 Patient characteristics associated with lack of conversion to functional AV access in patients starting hemodialysis with nonfunctional AV access or with catheter only

\begin{tabular}{|c|c|c|c|c|c|}
\hline \multirow[t]{3}{*}{ Characteristics } & \multicolumn{4}{|c|}{ Vascular access at baseline } & \multirow[t]{3}{*}{$P$-value for interaction ${ }^{\mathrm{a}}$} \\
\hline & \multicolumn{2}{|c|}{ Nonfunctional AV access } & \multicolumn{2}{|l|}{ Catheter only } & \\
\hline & $\mathrm{aOR}(95 \% \mathrm{Cl})$ & $P$-value & $\mathrm{aOR}(95 \% \mathrm{Cl})$ & $P$-value & \\
\hline Women & $1.25(1.10-1.43)$ & 0.0009 & $1.28(1.20-1.36)$ & $<0.0001$ & 0.9514 \\
\hline Age (1-year increase) & $1.01(1.01-1.02)$ & $<0.0001$ & $1.02(1.01-1.02)$ & $<0.0001$ & 0.0117 \\
\hline Primary renal disease & & 0.5615 & & $<0.0001$ & 0.0938 \\
\hline Hypertensive/Vascular & $0.94(0.73-1.22)$ & & $0.93(0.83-1.04)$ & & \\
\hline Diabetic nephropathy & $0.94(0.71-1.25)$ & & $0.84(0.74-0.95)$ & & \\
\hline \multicolumn{6}{|l|}{ Glomerulonephritis } \\
\hline Polycystic kidney disease & $1.11(0.76-1.61)$ & & $0.79(0.64-0.97)$ & & \\
\hline Other & $1.13(0.87-1.47)$ & & $1.19(1.07-1.33)$ & & \\
\hline Unknown & $1.00(0.75-1.34)$ & & $1.15(1.03-1.29)$ & & \\
\hline Diabetes & $0.92(0.77-1.10)$ & 0.3405 & $0.99(0.92-1.07)$ & 0.8856 & 0.6441 \\
\hline Number of cardiovascular como & & 0.0008 & & $<0.0001$ & 0.4444 \\
\hline \multicolumn{6}{|l|}{0} \\
\hline 1 & $1.19(1.01-1.40)$ & & $1.12(1.04-1.21)$ & & \\
\hline 2 & $1.27(1.04-1.54)$ & & $1.39(1.28-1.52)$ & & \\
\hline 3 & $1.45(1.16-1.82)$ & & $1.58(1.42-1.75)$ & & \\
\hline 4 or 5 & $2.09(1.55-2.82)$ & & $1.88(1.63-2.17)$ & & \\
\hline Lower limb amputation & $1.13(0.73-1.74)$ & 0.5884 & $1.26(1.07-1.47)$ & 0.0050 & 0.3740 \\
\hline Malignancy & $1.23(0.99-1.52)$ & 0.0592 & $1.65(1.51-1.79)$ & $<0.0001$ & 0.0056 \\
\hline Mobility status & & $<0.0001$ & & $<0.0001$ & 0.0105 \\
\hline \multicolumn{6}{|l|}{ Autonomous } \\
\hline Needs assistance & $1.41(1.17-1.69)$ & & $1.61(1.48-1.74)$ & & \\
\hline Totally dependent & $2.05(1.55-2.70)$ & & $2.90(2.56-3.28)$ & & \\
\hline Body mass index $\left(\mathrm{kg} / \mathrm{m}^{2}\right)$ & & 0.9333 & & 0.0003 & 0.0856 \\
\hline$<18.5$ & $1.03(0.73-1.47)$ & & $1.21(1.07-1.36)$ & & \\
\hline \multicolumn{6}{|l|}{$[18.5-25.0]$} \\
\hline$[25.0-30.0]$ & $1.01(0.86-1.19)$ & & $0.96(0.89-1.03)$ & & \\
\hline$\geq 30.0$ & $1.03(0.86-1.23)$ & & $0.85(0.78-0.94)$ & & \\
\hline Serum albumin (1-g/l increase) & $0.99(0.98-1.01)$ & 0.3773 & $0.99(0.99-1.00)$ & 0.0033 & 0.2750 \\
\hline Anemia (hemoglobin $<10 \mathrm{~g} / \mathrm{dl}$ ) & $0.95(0.83-1.10)$ & 0.5156 & $0.91(0.85-0.97)$ & 0.0027 & 0.6696 \\
\hline Predialysis ESA treatment & $1.12(0.98-1.27)$ & 0.0899 & $1.04(0.97-1.11)$ & 0.3031 & 0.3383 \\
\hline \multicolumn{2}{|c|}{ Estimated glomerular filtration rate (MDRD $\mathrm{ml} / \mathrm{min} / 1.73 \mathrm{~m}^{2}$ ) } & 0.0037 & & $<0.0001$ & 0.9829 \\
\hline $\mathrm{eGFR} \leq 5$ & $0.68(0.54-0.86)$ & & $0.75(0.68-0.83)$ & & \\
\hline $5<\mathrm{eGFR} \leq 10$ & $0.88(0.74-1.03)$ & & $0.91(0.84-0.99)$ & & \\
\hline \multicolumn{6}{|l|}{$10<e G F R \leq 15$} \\
\hline $15<\mathrm{eGFR} \leq 20$ & $1.11(0.83-1.48)$ & & $1.19(1.04-1.37)$ & & \\
\hline eGFR>20 & $1.38(0.90-2.12)$ & & $1.35(1.13-1.60)$ & & \\
\hline Facility type & & 0.0001 & & 0.0001 & 0.3805 \\
\hline \multicolumn{6}{|l|}{ In center } \\
\hline Satellite unit & $0.37(0.19-0.73)$ & & $0.59(0.42-0.82)$ & & \\
\hline Self-dialysis & $0.28(0.14-0.57)$ & & $0.48(0.35-0.65)$ & & \\
\hline
\end{tabular}


Table 2 Patient characteristics associated with lack of conversion to functional AV access in patients starting hemodialysis with nonfunctional AV access or with catheter only (Continued)

\begin{tabular}{llll}
\hline Facility ownership & & 0.0790 & 0.1452 \\
Public university & $0.77(0.66-0.91)$ & 0.6509 \\
Public non-university & $0.78(0.66-0.92)$ & $0.79(0.73-0.85)$ \\
Private for-profit & $1.11(0.88-1.40)$ & $0.94(0.85-1.05)$ \\
Private not-for-profit & & \\
\hline
\end{tabular}

${ }^{a} P$-value for interaction between patient characteristic and AV access at baseline. ORs were adjusted for year of hemodialysis initiation and for all variables in Table 2. Abbreviations: $a O R$ adjusted odds ratio, CI confidence interval, AV arteriovenous, ref reference, ESA erythropoiesis-stimulating agents, MDRD Modification of Diet in Renal Disease

US [2]. Discrepancies in mortality risk estimates associated with nonfunctional $\mathrm{AV}$ access at hemodialysis initiation between the 2 countries may, however, reflect differences in the rate of conversion to functional AV access after dialysis initiation, as our findings suggest. The availability of updated vascular access status during follow-up in the REIN registry enabled us to determine that patients with nonfunctional AV access at hemodialysis initiation had lower rates of functional AV access during the first 3 years of RRT than patients who started with functional AV access, but higher rates than patients who started with catheter alone. Our results indicate that the excess mortality risk in patients starting hemodialysis with a catheter, either because no AV access was placed or because it was nonfunctional, is limited to patients who remained on dialysis with a catheter. Thus, once a permanent vascular access was in place for patients with nonfunctional AV access at initiation, their mortality risk was similar to those with functional AV access at first dialysis. Nevertheless, despite adjusting for several potential confounders, we cannot completely rule out a selection effect, with healthier individuals chosen for $\mathrm{AV}$ access conversion, as an explanation of the better outcome of this subgroup of patients. Such a selection effect is at least partly indicated by the overall poorer health condition of patients who did not convert to a functional AV access, notably in the catheter only group. Moreover, patients with a catheter alone at baseline and subsequent functional AV access had the lower mortality risk among the studied groups.

These findings, however, are consistent with those from DOPPS, which showed that in patients initiating dialysis with a catheter, conversion to a permanent AV access was associated with an adjusted mortality HR of 0.69 (95\% CI, 0.55-0.85) [18]. Similarly, the HEMO study showed no difference in mortality risk between patients with longterm AV access versus those who converted from catheter in the preceding year of treatment [17]. Likewise, in prevalent dialysis patients treated in Fresenius Medical Care facilities, catheter conversion to AV access within a 4-month period was associated with a mortality risk in the following 8 months similar to that of patients with AV access from the outset of the follow-up [19].

Our finding that survival was similar in patients with functional AV access after hemodialysis initiation, regardless of their vascular access at the start, should not be interpreted as calling into question the fistula first

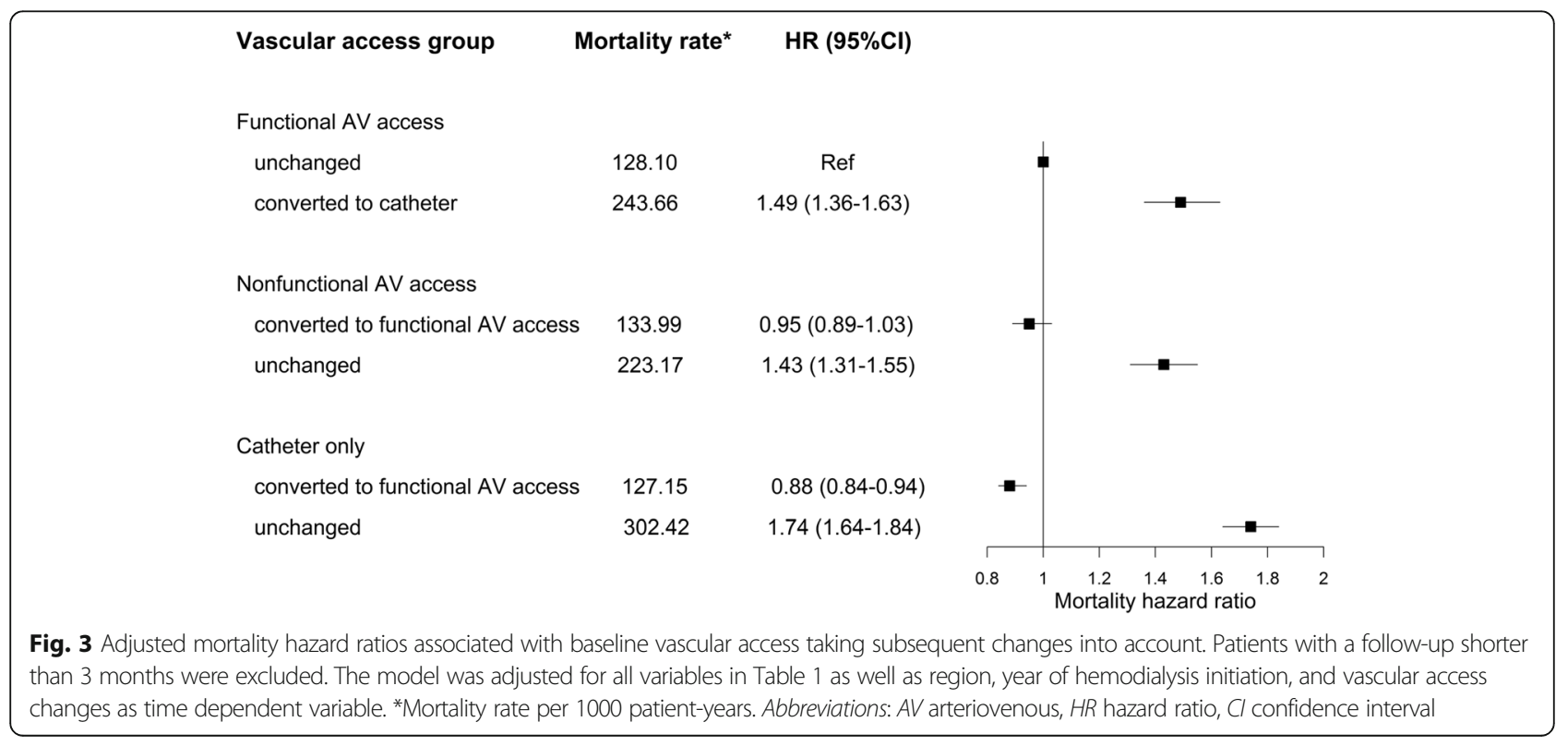


Table 3 Sensitivity analyses

\begin{tabular}{|c|c|c|}
\hline Sensitivity analyses: & $\begin{array}{l}\text { Setting changes } \\
\text { at the end of the } \\
\text { interval }\end{array}$ & $\begin{array}{l}\text { Limiting population to } \\
\text { those with at least one } \\
\text { annual update }\end{array}$ \\
\hline Vascular access group & \multicolumn{2}{|c|}{$\mathrm{HR}(95 \% \mathrm{Cl})$} \\
\hline \multicolumn{3}{|l|}{ Functional AV access } \\
\hline unchanged & 1 & 1 \\
\hline converted to catheter & $1.62(1.48-1.78)$ & $1.60(1.44-1.77)$ \\
\hline \multicolumn{3}{|l|}{ Nonfunctional AV access } \\
\hline $\begin{array}{l}\text { converted to } \\
\text { functional AV access }\end{array}$ & $1.05(0.97-1.13)$ & $0.98(0.91-1.06)$ \\
\hline unchanged & $1.25(1.15-1.35)$ & $1.55(1.41-1.69)$ \\
\hline \multicolumn{3}{|l|}{ Catheter only } \\
\hline $\begin{array}{l}\text { converted to } \\
\text { functional AV access }\end{array}$ & $1.02(0.96-1.08)$ & $0.90(0.84-0.95)$ \\
\hline unchanged & $1.53(1.45-1.61)$ & $1.94(1.83-2.06)$ \\
\hline \multicolumn{3}{|c|}{$\begin{array}{l}\text { Patients with a follow-up shorter than } 3 \text { months were excluded. The model } \\
\text { was adjusted for all variables in Table } 1 \text { as well as region, year of hemodialysis } \\
\text { initiation, and vascular access changes as time dependent variable. } \\
\text { Abbreviations: } A V \text { arteriovenous, } H R \text { hazard ratio, } \\
C I \text { confidence interval } \\
\text { Adjusted mortality hazard ratios associated with initial vascular access taking } \\
\text { subsequent changes into account }\end{array}$} \\
\hline
\end{tabular}

principle. In our study, only $63 \%$ of patients with nonfunctional AV access at initiation converted to a functional one. Moreover, the catheter use itself may have prevented conversion to a functional access for some patients: catheter use is associated with mortality risk, and some patients may have had catheter-related early deaths. Moreover, catheter use may contribute to subsequent $\mathrm{AV}$ access failure due to central venous stenosis $[5,31,32]$. Given that AV fistulae may never be successful for some fraction of patients because of their poor vascular condition, the potential of AV grafts for reducing catheter use should be considered. Studies in the US have shown similar outcomes for AV fistulae and AV grafts in some subpopulations [33, 34].

Major strengths of this study include the size and unselected nature of our registry-based population, which enable generalization of our results to France and other European countries having similar context. In addition, we were able to take major potential confounders into account in the multivariate analyses, including numerous comorbidities and treatment conditions. Lastly, updated information on vascular access was available, and very few patients were lost to follow-up.

Our study also has limitations. First, the prevalence of nonfunctional AV access may be underestimated due to missing AV creation dates. Because the presence of AV access itself at start is not recorded, but only its date of creation if any, we do not know how many patients among those with no reported creation date had no AV access and how many had a missing date for AV access creation. The percentage of missing dates is known, however, for patients who started with functional AV access (15\%). Simulation of missing date rates showed that their potential impact on the prevalence estimate of nonfunctional AV access would be low: for example, $10 \%$ instead of $9 \%$, if the missing date rate was $15 \%$ for both the functional and nonfunctional AV access groups, and $13 \%$, if this rate was twice as high (30\%) for the nonfunctional access group. Second, available data did not allow to specify whether the nonfunctional access was patent but not sufficiently matured, or failed and not salvageable. Finally, the vascular access update was interval-censored, which may have resulted in misclassification. Nevertheless, sensitivity analysis using the end of each interval provided consistent findings. Moreover, because annual updates in the REIN registry concern patients' permanent treatment, our data are likely to reflect outcomes associated with long-term use of a given vascular access.

\section{Conclusion}

In France with its relatively high rate of predialysis $\mathrm{AV}$ access creation, AV access is nonfunctional at hemodialysis initiation for a substantial percentage of patients. Importantly, conversion to functional AV access in patients who started on catheter is associated with similar mortality risk as compared to that of patients with functional AV access from the beginning. However, the reasons why a significant number of predialysis AV accesses never become functional require further investigation to identify potentially modifiable risk factors.

\section{Additional files}

Additional file 1: Prevalence of functional AV access at 12, 24, and 36 months according to the type of vascular access at hemodialysis initiation. Abbreviation: AV, arteriovenous. (TIF 1406 kb)

Additional file 2: Kaplan-Meier survival curves according to vascular access group at hemodialysis initiation. Abbreviation: AV, arteriovenous. (TIF 2362 kb)

Additional file 3: Crude and adjusted hazard ratios of mortality according to vascular access at first hemodialysis for patients followed for three months or more. (DOCX $12 \mathrm{~kb}$ )

\section{Abbreviations}

AV: Arteriovenous; Cl: Confidence interval; ESRD: End-stage renal disease; HR: Hazard ratio; REIN: Renal epidemiology and information network; RRT: Renal replacement therapy; US: United States

\section{Acknowledgements}

We thank all the registry participants, especially the nephrologists and professionals who collected the data and conducted the quality control. The dialysis units participating in the registry are listed in its annual report: http:// www.agence-biomedecine.fr/IMG/pdf/rapport_rein2013.pdf. Part of this work was presented orally at the 53rd congress ERA-EDTA in Vienna, Austria, May 21st-24th.

\section{Funding}

This work was supported by a research grant from the French Biomedicine Agency, Recherche REIN. 


\section{Availability of data and materials}

The restrictions due to French Personal data protection regulation (CNIL) prohibit the authors from making the minimal data set publicly available. The access to the data of the REIN registry is governed by a charter. It implies the approval by the REIN scientific board which analyses each request. Information about the data of the REIN registry can be requested by mail to Dr Christian Jacquelinet who manages the REIN registry at the French Biomedicine Agency (christian.jacquelinet@biomedecine.fr).

\section{Authors' contributions}

Conception and design were done by NAP, RC, ZM and BS. Statistical analysis were done by NAP. Interpretation of the data and drafting the article were done by NAP, RC, MM, ML, CA, CJ, ZM and BS. All authors read and approved the final manuscript.

\section{Competing interests}

The authors declare that they have no competing interests.

\section{Consent for publication}

Not applicable.

\section{Ethics approval and consent to participate}

The REIN registry was approved by the relevant French committees, the Comité consultatif sur le traitement de l'information en matière de recherche (CCTIRS) and the Commission nationale de l'informatique et des libertés (CNIL N 903188). For population-based registries requiring exhaustiveness, French regulations require that patients be informed by the clinic that they can choose not to participate (opt-out). This study was approved by the French Biomedicine Agency and included patients' information which have been anonymized and de-identified directly in the database and before the extraction for analysis.

\section{Author details}

${ }^{1}$ Paris Saclay University, Paris-Sud Univ, UVSQ, CESP, INSERM, Renal and Cardiovascular Epidemiology Team, Villejuif, France. ${ }^{2}$ Division of Vascular Surgery, Ambroise Paré University Hospital, Boulogne-Billancourt, France. ${ }^{3}$ Lyon-Sud University Hospital, Pierre-Bénite, France. ${ }^{4}$ CHRU Nancy, Pôle S2R, Epidémiologie et Evaluations Cliniques, Nancy, France. ${ }^{5}$ Inserm, CIC-1433 Epidémiologie Clinique, Nancy, France. ${ }^{6}$ Biomedicine Agency, Saint Denis, France. 7 Division of Nephrology, Ambroise Paré University Hospital, Boulogne-Billancourt, France.

Received: 29 July 2016 Accepted: 15 February 2017 Published online: 22 February 2017

\section{References}

1. Ravani P, Palmer SC, Oliver MJ, Quinn RR, MacRae JM, Tai DJ, et al. Associations between hemodialysis access type and clinical outcomes: a systematic review. J Am Soc Nephrol. 2013;24(3):465-73.

2. Grubbs V, Wasse $H$, Vittinghoff $E$, Grimes BA, Johansen $K L$. Health status as a potential mediator of the association between hemodialysis vascular access and mortality. Nephrol Dial Transplant. 2014;29(4):892-8.

3. Malas MB, Canner JK, Hicks CW, Arhuidese IJ, Zarkowsky DS, Qazi U, et al. Trends in incident hemodialysis access and mortality. JAMA Surg. 2015;150(5):441-8.

4. Al-Jaishi AA, Lok CE, Garg AX, Zhang JC, Moist LM. Vascular access creation before hemodialysis initiation and use: a population-based cohort study. Clin J Am Soc Nephrol. 2015;10(3):418-27.

5. Xue H, Ix JH, Wang W, Brunelli SM, Lazarus M, Hakim R, et al. Hemodialysis access usage patterns in the incident dialysis year and associated catheterrelated complications. Am J Kidney Dis. 2013;61(1):123-30.

6. Ng LJ, Chen F, Pisoni RL, Krishnan M, Mapes D, Keen M, et al. Hospitalization risks related to vascular access type among incident US hemodialysis patients. Nephrol Dial Transplant. 2011;26(11):3659-66.

7. Tordoir J, Canaud B, Haage P, Konner K, Basci A, Fouque D, et al. EBPG on vascular access. Nephrol Dial Transplant. 2007;22 Suppl 2:ii88-ii117.

8. 2006 Updates Clinical Practice Guidelines and Recommendations [Internet]. [cited 2016 Jan 5]. Available from: https://www.kidney.org/sites/default/files/ docs/12-50-0210_jag_dcp_guidelines-va_oct06_sectionc_ofc.pdf

9. Sidawy AN, Spergel LM, Besarab A, Allon M, Jennings WC, Padberg FTJ, et al. The Society for Vascular Surgery: clinical practice guidelines for the surgical placement and maintenance of arteriovenous hemodialysis access. J Vasc Surg. 2008;48(5 Suppl):2S-25S.

10. Vassalotti JA, Jennings WC, Beathard GA, Neumann M, Caponi S, Fox CH, et al. Fistula first breakthrough initiative: targeting catheter last in fistula first. Semin Dial. 2012;25(3):303-10.

11. Noordzij M, Jager KJ, van der Veer SN, Kramar R, Collart F, Heaf JG, et al. Use of vascular access for haemodialysis in Europe: a report from the ERA-EDTA Registry. Nephrol Dial Transplant. 2014;29(10):1956-64.

12. Rapport REIN 2013 [Internet]. [cited 2016 Jan 5]. Available from: http://www. agence-biomedecine.fr/IMG/pdf/rapport_rein2013.pdf

13. Hod T, Patibandla BK, Vin Y, Brown RS, Goldfarb-Rumyantzev AS. Arteriovenous fistula placement in the elderly: when is the optimal time? J Am Soc Nephrol. 2015;26(2):448-56.

14. Pisoni RL, Zepel L, Port FK, Robinson BM. Trends in US vascular access use, patient preferences, and related practices: an update from the US DOPPS practice monitor with international comparisons. Am J Kidney Dis. 2015;65(6):905-15.

15. Asano M, Thumma J, Oguchi K, Pisoni RL, Akizawa T, Akiba T, et al. Vascular access care and treatment practices associated with outcomes of arteriovenous fistula: international comparisons from the Dialysis Outcomes and Practice Patterns Study. Nephron Clin Pract. 2013;124(1-2):23-30.

16. Saran R, Dykstra DM, Pisoni RL, Akiba T, Akizawa T, Canaud B, et al. Timing of first cannulation and vascular access failure in haemodialysis: an analysis of practice patterns at dialysis facilities in the DOPPS. Nephrol Dial Transplant. 2004;19(9):2334-40.

17. Allon M, Daugirdas J, Depner TA, Greene T, Ornt D, Schwab SJ. Effect of change in vascular access on patient mortality in hemodialysis patients. Am J Kidney Dis. 2006;47(3):469-77.

18. Bradbury BD, Chen F, Furniss A, Pisoni RL, Keen M, Mapes D, et al. Conversion of vascular access type among incident hemodialysis patients: description and association with mortality. Am J Kidney Dis. 2009;53(5):804-14.

19. Lacson EJ, Wang W, Lazarus JM, Hakim RM. Change in vascular access and mortality in maintenance hemodialysis patients. Am J Kidney Dis. 2009;54(5):912-21.

20. Kalloo S, Blake PG, Wish J. A patient-centered approach to hemodialysis vascular access in the Era of fistula first. Semin Dial. 2016;29(2):148-57.

21. Couchoud C, Stengel B, Landais P, Aldigier J-C, de Cornelissen F, Dabot C, et al. The renal epidemiology and information network (REIN): a new registry for end-stage renal disease in France. Nephrol Dial Transplant. 2006;21(2):411-8.

22. van Buuren S. Multiple imputation of discrete and continuous data by fully conditional specification. Stat Methods Med Res. 2007;16(3):219-42.

23. Lee KJ, Carlin JB. Multiple imputation for missing data: fully conditional specification versus multivariate normal imputation. Am J Epidemiol. 2010;171(5):624-32.

24. Noordzij M, Leffondré K, van Stralen KJ, Zoccali C, Dekker FW, Jager KJ. When do we need competing risks methods for survival analysis in nephrology? Nephrol Dial Transplant. 2013;28(11):2670-7.

25. Andersen PK. Repeated assessment of risk factors in survival analysis. Stat Methods Med Res. 1992;1(3):297-315.

26. Hecking M, Bieber BA, Ethier J, Kautzky-Willer A, Sunder-Plassmann G, Säemann MD, et al. Sex-specific differences in hemodialysis prevalence and practices and the male-to-female mortality rate: the Dialysis Outcomes and Practice Patterns Study (DOPPS). PLoS Med. 2014;11(10):e1001750.

27. Wasse H, Hopson SD, McClellan W. Racial and gender differences in arteriovenous fistula use among incident hemodialysis patients. Am J Nephrol. 2010;32(3):234-41.

28. Ocak G, Rotmans Jl, Vossen CY, Rosendaal FR, Krediet RT, Boeschoten EW, et al. Type of arteriovenous vascular access and association with patency and mortality. BMC Nephrol. 2013;14:79.

29. Pisoni RL, Young EW, Dykstra DM, Greenwood RN, Hecking E, Gillespie B, et al. Vascular access use in Europe and the United States: results from the DOPPS. Kidney Int. 2002;61(1):305-16.

30. Saran R, Elder SJ, Goodkin DA, Akiba T, Ethier J, Rayner HC, et al. Enhanced training in vascular access creation predicts arteriovenous fistula placement and patency in hemodialysis patients: results from the Dialysis Outcomes and Practice Patterns Study. Ann Surg. 2008;247(5):885-91.

31. Lok CE. Fistula first initiative: advantages and pitfalls. Clin J Am Soc Nephrol. 2007;2(5):1043-53 
32. Zhu M, Zhang W, Zhou W, Zhou Y, Fang Y, Wang Y, et al. Initial hemodialysis with a temporary catheter is associated with complications of a later permanent vascular access. Blood Purif. 2014;37(2):131-7.

33. Yuo TH, Chaer RA, Dillavou ED, Leers SA, Makaroun MS. Patients started on hemodialysis with tunneled dialysis catheter have similar survival after arteriovenous fistula and arteriovenous graft creation. J Vasc Surg. 2015;62(6):1590-97.e2

34. DeSilva RN, Patibandla BK, Vin Y, Narra A, Chawla V, Brown RS, et al. Fistula first is not always the best strategy for the elderly. J Am Soc Nephrol. 2013;24(8):1297-304

Submit your next manuscript to BioMed Central and we will help you at every step:

- We accept pre-submission inquiries

- Our selector tool helps you to find the most relevant journal

- We provide round the clock customer support

- Convenient online submission

- Thorough peer review

- Inclusion in PubMed and all major indexing services

- Maximum visibility for your research

Submit your manuscript at www.biomedcentral.com/submit
Biomed Central 